\title{
Diamond-forming Fluids: their origin and evolution
}

\author{
O. Navon ${ }^{1}$, O. Klein-BenDavid ${ }^{1,2}$, Y. Weiss ${ }^{1}$ \\ 1 Institute of Earth Sciences, The Hebrew University of Jerusalem, 91904 Israel \\ 2 Department of Earth Sciences, Durham University, Science Labs, Durham, DH1 3LE, UK
}

\begin{abstract}
Introduction
Microinclusions-bearing fibrous and cloudy diamonds carry the best available samples of diamond forming fluids. Studying their chemical composition and their evolution is important for understanding the formation of diamonds within the Earth's mantle.

Klein-BenDavid et al. (2007) summarized the available data and defined the compositions of three endmembers: carbonatitic (rich in carbonate, $\mathrm{CaO}, \mathrm{MgO}$ and $\mathrm{FeO}$ ), hydrous-silicic (rich in water, $\mathrm{SiO}_{2}, \mathrm{Al}_{2} \mathrm{O}_{3}$ and $\mathrm{K}_{2} \mathrm{O}$ ) and hydrous-saline (rich in water, $\mathrm{Cl}, \mathrm{K}$ and $\mathrm{Na}$ with $\mathrm{K}>\mathrm{Na}$ ). They examined possible relations between the HDFs and preferred a model, in which a carbonatitic HDF cools, fractionates and separates immiscibly to form two arrays of HDFs: between carbonatitic and saline and between carbonatitic and silicic. The carbonatitic HDFs was further divided into high- and low-Mg components (Navon et al., 2008).
\end{abstract}

\section{The Closed System Fractionation/Melting Model}

Figure 1 presents the variation of various oxides in the HDFs together with some experimental melts of carbonated peridotite (Dasgupta and Hirschman, 2007; Brey et al. 2008). The experiments determined the near-solidus compositions of carbonate peridotite or harzburgite (large orange triangles) and some higher temperature compositions that evolve (with some mismatch) towards kimberlitic compositions. The diagrams showing the variation of $\mathrm{SiO}_{2}$ and $\mathrm{Cl}$ vs. $\mathrm{MgO}$ (and similar ones for $\mathrm{Al}_{2} \mathrm{O}_{3}$ and $\mathrm{Na}_{2} \mathrm{O}$ ) best separate the three components: the carbonatitic at high $\mathrm{MgO}$ contents, the silicic at high silica and little $\mathrm{Cl}$ and the saline with little silica and high $\mathrm{Cl}$. The plots clearly show the basis for the fractionation model. Upon cooling, kimberlite-like melts cool, fractionate silicates, and evolves towards the solidus melts of carbonate peridotite. As they carry low melting point components, such as water, $\mathrm{K}$ and $\mathrm{Cl}$, crystallization does not end there, but rather continues towards the carbonatitic HDFs. There carbonates join silicates and later replace them as the fractionating phase. When the immiscibility gap between silicic and saline compositions is reached the melt separate immiscibly and the composition fall along the two arrays.

In such a close system model, it is not possible to determine the direction of evolution. Similar fluids may form and evolve in the reverse direction during heating and melting. The fractionation model was preferred because it seems simpler to separate one fluid into two immiscible ones, than to produce saline and silicic HDFs separately and mix them to form the carbonatitic one, and because it is easier to accept diamond growth during cooling.

A role for fractionation is also suggested by some of the trace elements data (Weiss et al. 2008a). For example, the range of $\mathrm{Th} / \mathrm{Nb}$ and $\mathrm{La} / \mathrm{Nb}$ shown in Figure 2 may be easily explained by fractionation of rutile that scavenges these elements. Removal of a $\mathrm{TiO}_{2}$-bearing phase is independently dictated by the major element data, where $\mathrm{TiO}_{2}$ concentration does not rise during the extensive fractionation from carbonatitic to silicic HDF. The lower concentration of $\mathrm{Zr}$, Hf and $\mathrm{U}$ in the saline HDFs relative to the carbonatitic ones (Figure 2) suggests removal of zircon. Again, gradual dissolution of rutile or zircon during melting will have a similar effect. So the direction of the process cannot be constrained.

\section{Problems in the Fractionation Model}

The best way to discriminate between fractionation and melting is to trace the evolution of the fluids during the growth of individual diamonds. Unfortunately, most microinclusion carry HDFs of limited compositional range with random variation during growth. Where clear zoning in inclusion chemistry was found, it was associated with sharp change in CL intensity and in carbon isotopic ratio, indicating two distinct growth events. Small consistent trends are found in a few diamonds, in most $\mathrm{CaO}$ increases and $\mathrm{SiO}_{2}$ decreases, but other show the opposite trend. Last, in a Kankan coated diamond consisting of three distinct growth zones, silica concentrations increase outward in the inner and outer coat, but decrease in the middle zone (Weiss et al. 2008b). Thus, not only a preferred direction was not found, it became clear that one-stage fractionation/melting models can not explain all data.

The recent determination of $\mathrm{Sr}-\mathrm{Nd}-\mathrm{Pb}$ radiogenic isotope ratios of the HDFs (Klein-BenDavid et al., 2008) adds to the complex picture. Ratios span a large range and call for involvement of fluids from different sources. Intra-diamond variation was also found. Models with a single parental melt can no longer explain the available data.

While fractionation and melting may play a role in forming the various end members, more complex processes, such as fluid mixing or fluid-rock interaction must be invoked as well.

\section{The Safonov-Perchuk-Litvin model}

Safonov et al. (2007) performed high P-T experiments in the $\mathrm{CaMgSi}_{2} \mathrm{O}_{6}-\left(\mathrm{Na}_{2} \mathrm{CO}_{3}, \mathrm{CaCO}_{3}\right)-\mathrm{KCl}$ system and confirmed an immiscibility between silicic and saline 

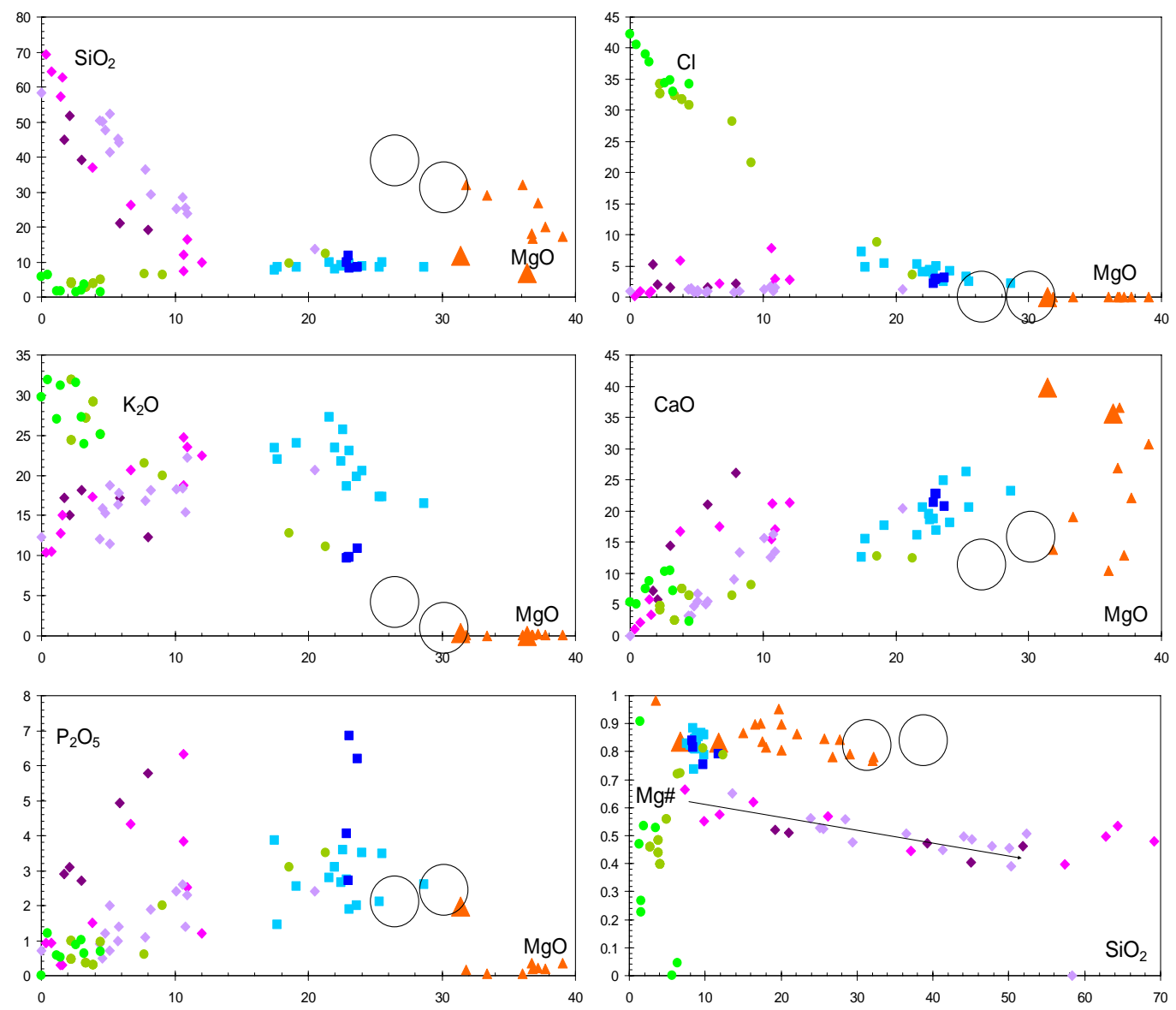

Figure 1. Major element variations of HDFs. Circles - saline HDFs from South Africa (bright green) and Canada (olive green). Diamonds - low-Mg carbonatitic to silicic HDFs from Siberia (pink) Botswana (lavender) and South Africa (violet). Squares high-Mg carbonatitic HDFs from Kankan, Guinea (blue) and Siberia (sky blue). Triangles - Experimental melts; large triangles near solidus compositions of hartzburgite and peridotite (Brey et al. 2008; Dasgupta and Hirschmann, 2007). Each point represent the average composition of the inclusions in a single diamond. In the case of the zoned diamond, ON-DVK-294, the four olive circles with highest $\mathrm{MgO}$ contents represent, from right to left, the carbonatitic end-member composition, the average composition of the inclusions in the outer, carbonatitic zone, the average for the inner saline inner coat and the saline endmember composition for that diamond (Klein-BenDavid et al., 2004). Also shown are the average compositions of Group I and Group II kimberlites (circular baloons, Becker and le Roex, 2006).

melts. However, they found out that with falling temperatures, the silicic and saline immiscible melts react with the pyroxene and evolve towards a single carbonatitic composition. Further work with garnet and olivine instead of pyroxene agrees with the above findings.

Based on their results they constructed a model where a chloride-carbonate melt interacts with silicate mantle rocks and induces the formation of a second melt phase of silicate-carbonate composition. The model suggests that diamonds grow in both melts when the two cool and evolve towards a single melt phase of carbonatitic composition. Melts of both arrays evolve and converge as they are trapped in the diamonds. If saline melt of one isotopic composition interacts with a mantle rock of different composition, the model can explain a range of isotopic ratios.

\section{Problems with the Safonov-Perchuk-Litvin model}

The experiments of Safonov et al. (2007) were conducted in an anhydrous system. This prevented the formation of silicic HDF (supercritical fluids or melts) at temperatures below the solidus of the experimental system. The range of silicic-carbonatitic fluids that were formed is limited and does not extend to high to $\mathrm{SiO}_{2}$ contents exhibited by the highly silicic HDFs (up to $~ 50 \mathrm{wt} \%$ in the experiments but up to $70 \mathrm{wt} \%$ in the HDFs, volatile free basis). It is possible to reach higher $\mathrm{SiO}_{2}$ contents if the saline melt interacts with coesite-eclogites rather than with diopside, however, it is hard to see how an $\mathrm{HDF}$ with high $\mathrm{SiO}_{2}$ and very low $\mathrm{MgO}$ and $\mathrm{CaO}$ evolves towards a carbonatitic composition by fractionating silicates, as suggested by the model. Trace element budgets are also problematic. As seen in Figure 2, Ta and $\mathrm{Nb}$ contents of both silicic and saline HDFs are low. Their mixing and fractionation cannot produce the much higher concentrations observed in the carbonatitic HDFs. In principle, rutile dissolution could provide the necessary $\mathrm{Nb}$ and $\mathrm{Ta}$, but is not likely to take place during cooling and increasing carbonatitic character. Last, as is the case for any single stage model, the model cannot explain the contrasting trends of evolution found in the zoned Kankan diamond, or the observation that it is not common to find saline and silicic diamonds in the same mine. In all studied cases, one assemblage dominates, with none or only one or two samples of the other fluid. 


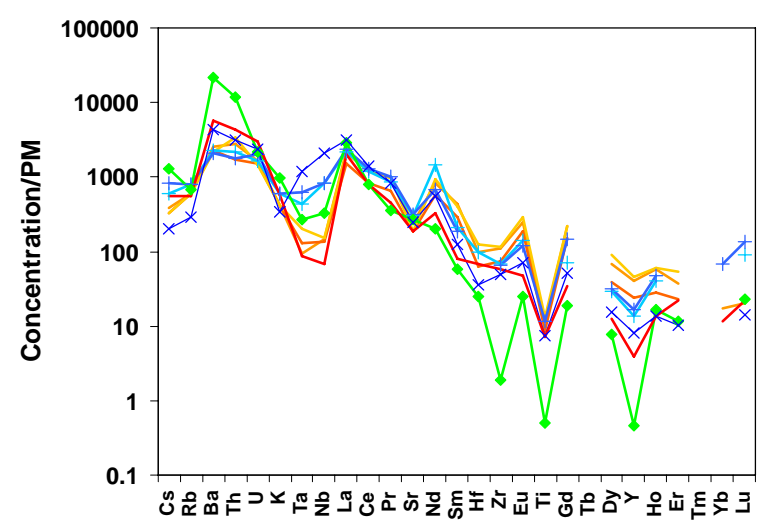

Figure 2. Trace element pattern in Kankan HDFs. Red silicic HDFs, thick blue lines - low-Mg and thin blue with Xs - high-Mg carbonatitic HDFs. The green thick line denotes the average composition of saline HDFs from Diavik, Canada.

\section{Separating the arrays}

Close examination of the arrays in Figure 1 reveals that the silicic-carbonatitic and saline-carbonatitic arrays do not merge into a single carbonatitic composition. In the $\mathrm{SiO}_{2}-\mathrm{MgO}$ plot they merge at $11 \mathrm{wt} \% \mathrm{MgO}$, while in the Cl-MgO one they merge at $\sim 18-20 \%$. In plots of $\mathrm{K}_{2} \mathrm{O}$ and $\mathrm{CaO}$, the arrays do not merge and cross each other at $~ 8-10 \mathrm{wt} \%$ and 4-5 wt\% MgO, respectively. If each array is examined individually, the Diavik saline-carbonatitic array extends to the high-Mg carbonatites. In fact, the carbonatitic end-member composition of Diavik (olive green circle at $21.3 \mathrm{wt} \%$ $\mathrm{MgO}$ ) is almost identical in composition to the Kankan high-Mg carbonatitic HDFs (blue squares) in all diagrams.

In most plots, the experimental near-solidus melts of carbonated peridotite lie on the extension of this array to high MgO values. Following Safonov et al. (2007) we suggest the possibility that the high-Mg carbonatitic HDFs form during interaction of saline HDFs with peridotitic rocks. The saline HDF lowers solidus temperatures relative to the carbonate-peridotite system and solidus composition shifts to that of the high-Mg carbonatitic HDFs and is enriched in $\mathrm{Cl}, \mathrm{K}$ and $\mathrm{Na}$.

In some plots, the compositions of saline HDFs, HighMg carbonatitic HDFs and near-solidus melt do not lie on a straight line, indicating that they do not simply mix, but rather interact with each other and with the solid phases during melting/metasomatism. Such interaction may take place when hot saline HDF penetrates a carbonate peridotite, induces melting and upon cooling, the immiscible melts merge into the high-Mg carbonatitic composition. Alternatively, in the case of rising temperatures, heating of a K-, Cl- and carbonate-bearing rock would lead to formation of carbonatitic HDF. With further heating, the carbonatitic HDF grows more silicic, evolves towards kimberlites and exsolves the excess $\mathrm{Cl}$ and alkalis as immiscible saline melt. The P2O5-MgO plot, where the high-Mg carbonatitic HDF is richer in P2O5 compared with both the saline HDF and the near solidus melts, reminds us that more the role of apatite, rutie and mica should also be explored.
Fluids of the silicic-carbonatitic array may form during melting of eclogitic source rock. Again, the source should be pre-enriched, or melt during interaction with enriched HDFs. The Safonov-Perchuk-Litvin model may be applicable in such a system as the compositions of their experimental silicate-carbonate melts fall close to that of the low-Mg carbonatitic HDFs. This array may extend to the high-Mg compositions as well. This is hinted by the differences in $\mathrm{K}_{2} \mathrm{O}$ between the Udachnaya and Kankan HDFs, and the straight line from the silicic-carbonatitic array to the Udachnaya data Fig. 1c. The mutual occurrence of both high- and low-Mg HDFs in the suites from Udachnaya, Snap Lake and Kankan also supports this suggestion.

\section{Conclusions}

The separation of the two arrays and the connection with near solidus melts is attractive in that it allows interaction and exchange between HDFs, mantle rocks and near-solidus melts of carbonate peridotites and eclogites. It also strengthens the connection to kimberlites by providing an enriched endmember to "mix" with the melts of the carbonate peridotite in forming kimberlites. The similar trace elements patterns of kimberlites and HDFs (Weiss et al., 2008) further support this possibility.

\section{References}

Becker, M., le Roex, A. P., 2006. Geochemistry of South African On- and Offcraton, Group I and Group II Kimberlites: Petrogenesis and Source Region Evolution. Journal of Petrology, 47, 673-703.

Brey, G.P., Bulatov, V.K., Girnis, A.V., Lahaye, Y., 2008. Experimental melting of carbonated peridotite at 610GPa. Journal of Petrology, 49, 797-821.

Dasgupta, R., Hirschmann, M.M., 2007. A modified iterative sandwich method for determination of near-solidus partial melt compositions. II. Application to determination of near-solidus melt compositions of carbonated peridotite. Contributions to Mineralogy and Petrology 154(6), 647-661.

Klein-BenDavid, O., Izraeli, E. S., Hauri, E., Navon, O., 2004. Mantle fluid evolution-a tale of one diamond. Lithos, 77, 243- 253.

Klein-BenDavid, O., Izraeli, E. S., Hauri E., and Navon O., (2007) Fluid inclusions in diamonds from the Diavik mine, Canada: the evolution of diamond-forming fluids. Geochimica et Cosmochimica Acta 71(3), 723-744.

Klein-BenDavid, O., Pearson, D. G., Cantigny, P., Nowell, G. M., 2008. Origins of diamond forming fluids constraints from a coupled Sr-Nd isotope and trace element approach. 9th IKC, Extended Abstracts.

Navon, O., Klein-BenDavid, O., Logvinova, A. M. et al., 2008. Yakutian Diamond-forming fluids and the evolution of carbonatitic high-density fluids. 9th IKC, Extended Abstracts.

Safonov, O. G., Perchuk, L. L., Litvin, Y. A., 2007. Melting relations in the chloride-carbonate-silicate systems at high-pressure and the model for formation of alkalic diamond-forming liquids in the upper mantle. Earth and Planetary Science Letters 253(1-2), 112-128.

Weiss, Y., Griffin, W.L., Harris, J.W. and Navon, O. 2008a Diamond-forming Fluids and Kimberlites: The Trace Element Perspective. 9th IKC, Extended Abstracts.

Weiss, Y., Kessel, R., Griffin, W. L., Kiflawi, I., Bell, D. R, Harris J. W., Navon, O., 2008b. Diamond forming fluids from Kankan, Guinea: major and trace element study. 9th IKC, Extended Abstracts. 